II Congreso Internacional Estéticas Híbridas de la Imagen en Movimiento: Identidad y Patrimonio

20 -22 octubre 2021. Universitat Politècnica de València Doi: https://doi.org/10.4995/EShID2021.2021.13240

\title{
En el parque
}

\author{
Rubén Marín Ramos ${ }^{1}$ \\ ${ }^{1}$ Universitat Politècnica de València \\ rumara1@alumni.upv.es
}

\begin{abstract}
In the park (2021) is a video project that raises questions related to desire, privacy and seeing and being seen, but it also alludes to the concept of the filmic device and creative strategies in contemporary audiovisuals. A voyeuristic game in which everyone observes and is observed, inspired by Kohei Yoshiyuki's photographic series The park (1971-1973). This flow of gazes seems, on the one hand, to invite the spectator to have an intrusive, almost pornographic vision, but which, in reality, is immediately curbed and disarticulated to the point of being ridiculed through the game that is established between the participants. The pre-established protocol of filming themselves eludes any kind of narrative, instead, there is a determination for formal experimentation and a willingness to recreate themselves through audiovisual tools.
\end{abstract}

Keywords: experimental cinema, voyeurism, creative dispositive, rules, game

\section{Resumen}

En el parque (2021) es un proyecto videográfico que plantea cuestiones relacionadas con el deseo, la privacidad, el ver y el ser visto, pero también alude al concepto de dispositivo de creación y al de estrategias creativas en el audiovisual contemporáneo. Un juego voyerístico en el que todos observan y son observados que se inspira en la serie fotográfica The park (1971-1973) de Kohei Yoshiyuki. Este flujo de miradas parece, por un lado, invitar al espectador a tener una visión intrusiva, casi pornográfica, pero que, en realidad es inmediatamente frenada y desarticularla hasta el punto de ser ridiculizada a través del juego que se establece entre los participantes. El protocolo preestablecido de filmarse a sí mismos elude cualquier tipo de narrativa, en su lugar, se evidencia la determinación por la experimentación formal y la disposición para recrearse por medio de las herramientas audiovisuales.

Palabras clave: cine experimental, voyerismo, dispositivo creativo, reglas, juego 


\section{Descripción de la obra}

En el parque (2021) es una pieza videográfica de algo menos de siete minutos, realizada en blanco y negro, con cuatro videocámaras, analógicas y digitales. Para su realización se invitó a un grupo de amigos a grabarse unos a otros mientras charlaban, bebían, fumaban o corrían en una zona previamente delimitada de un parque, que bien podía ser frecuentada para la práctica del cruising. La pantalla aparece divida en dos, uno para cada formato de video empleado. En ambos lados, se aprecian vistas del parque por la noche, zonas en penumbra con arbustos, árboles, etc., y, sin una narración evidente, poco a poco empieza a parecer gente, unos tumbados en el suelo, otros grabando escondidos tras los árboles, corriendo con la cámara, o sentados revisando el material grabado.

La pieza no tiene diálogos, pero si banda sonora, que se compone de tres pistas: una de ruido blanco característico de la señal de video y que se reparte de forma uniforme por toda la pieza; otra, con un ruido intermitente más grave, que aparece sincronizado con los "fallos" que presenta una de las cámaras de video VHS-C (los cuales producen que la imagen se desplaza lateralmente); y una última, con parte del sonido ambiente recogido durante la grabación, pero que apenas es perceptible.

La pieza ha sido realizada en el antiguo cauce del rio Turia, en Valencia. Los participantes únicamente fueron avisados de cómo se iba a llevar a cabo la pieza una vez estaban en la localización. Para su realización llevamos al lugar todo el material necesario: cuatro cámaras, dos grabadoras de audio, micrófonos para recoger el sonido ambiente y algo para beber y picar. La grabación se llevó a cabo en el mes de marzo de 2021 , cuando el toque de queda en Valencia era a las $22 \mathrm{~h}$, y dadas las escasas horas de oscuridad que tuvimos, la pieza se tuvo que grabar en dos noches diferentes. En ella han participado: Ana Císcar, Francisco Cerón, Silvia Monterrosa, Sergio Martín, Enrique García, Claudia Padureanu, Leticia Galera y Carlos Linares, que se intercalaron libremente el uso de las cámaras, así como de la grabadora de audio. 


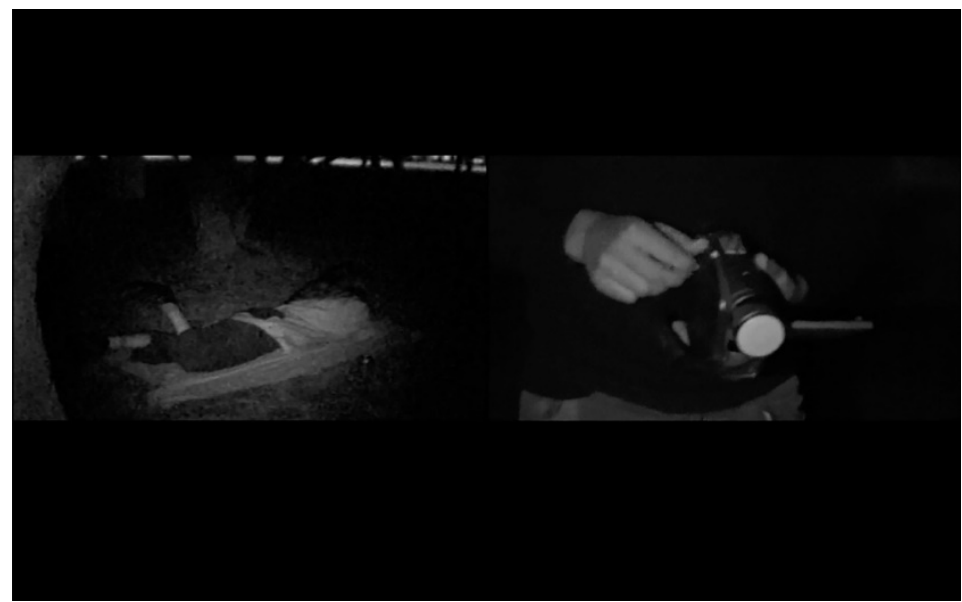

Fig. 1: Fotograma de En el parque (2021).

\section{La mirada voyerista}

El cine ha contribuido directamente en el desarrollo de una visión y un entender los acontecimientos del mundo a través de una mirada voyerista. Antes, desde el anonimato que ofrecia la sala de cine a oscuras, luego desde la televisión y la privacidad de nuestras hogares, y ahora también, desde nuestros dispositivos móviles y ordenadores personales. Esta mirada voyeurista, elimina los matices de la vida, homogeiniza el mundo, y nos hace observar con la misma indiferencia, anuncios de perfumes, un reality show, escenas de extremada violencia en una película de ficción o imágenes de la guerra en Siria. Miramos sin ser observados, sin tomar partido, y nuestra mirada se desinsibiliza y se deshumaniza.

Por otro lado, la visibilidad siempre se ha relacionado con el poder del que mira sobre el objeto o sujeto mirado. Por lo tanto, hablar de la mirada voyerista en el cine, es también hacerlo de la mirada masculina. Como Laura Mulvey nos enseñó, esta situación de poder que nos permite observar sin ser observados, nos identifica y nos hace ver el mundo a través del sujeto masculino. Tal es el caso de Rape (1969) de Yoko Ono, en el que la mujer convertida en el objeto de deseo, es acechada y violada por la cámara. La mujer, como objeto examinado por la cámara, se vuelve absolutamente indefensa ante esa mirada obsesiva. Asimismo, la mirada voyerista guarda un cierto paralelismo con nuestra cultura consumista, es decir, el deseo de querer ver siempre más, más de cerca, más privado, "lo nunca visto". Este esceso de imágenes y de información, en realidad se convierten en un velo, como señalaba Abu Ali, el cual no nos deja ver y nos hace más ignorantes. 
En el parque se suma a los trabajos que, a lo largo de la historia de la fotografía y de la imagen en movimiento, se han planteado estas cuestiones en relación al voyerismo, así como a la vigilancia y la privacidad, ideando métodos y formas de trabajo menos invasivas, más éticas, en el que por ejemplo, se descuida la calidad fotográfica en favor de otro tipo de aspectos más participativos, performativos, reflexivos o conceptuales. Pero también, al tipo de trabajos que, como la antes mencionada Rape de Yoko Ono, así como la serie fotográfica Camera Club (1996) de Chris Verene, o el trabajo de Kohei Yoshiyuk In the park (1971-1973), en el que se inspira nuestra pieza, han tratado de mostrar y criticar esta omnipresencia de la mirada masculina. Yoshiyuk capturó mediante una cámara equipada con un flash electrónico y con un filtro especial, a voyeurs que observaban escondidos (a veces incluso invadían la escena) a parejas que mentenían relaciones sexuales en tres parques diferentes de Tokio. El fotógrafo japonés establece un interesante juego de miradas, con el que consigue un efecto similar al de mise en abîme, en el que todos nos convertimos en voyeristas, los hombres que observan a las parejas, el mismo fotógrafo, y el observador de la propias fotografías.

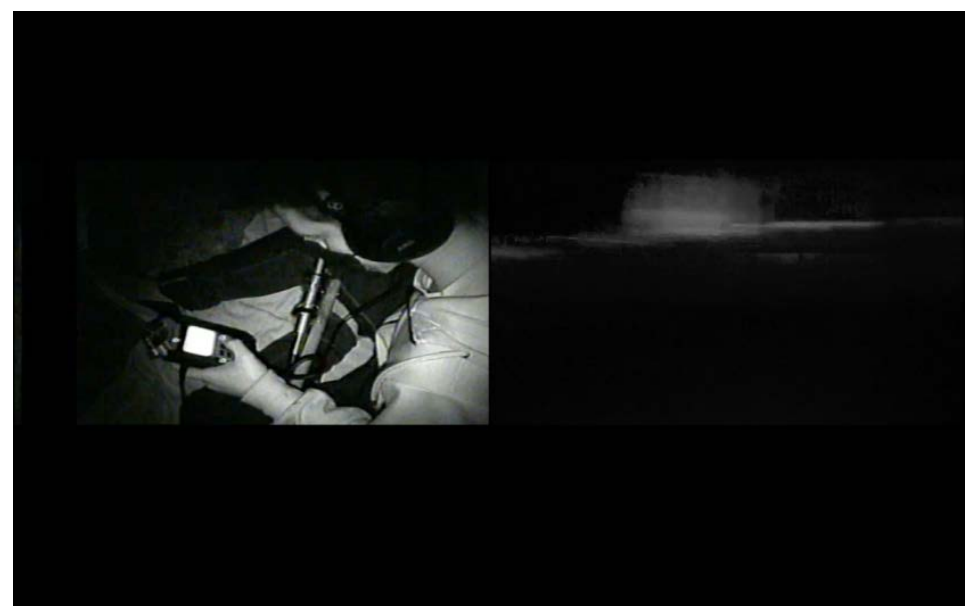

Fig. 2: Fotograma de En el parque (2021).

\section{Dispositivo de creación y juego}

La noción de dispositivo como herramienta de creación artística que reivindican teóricos como Consuelo Lins (2004-2008), Cezar Migliorin (2005-2008) o Jean Claude Bernardet (2004), entre otros, es fundamental para este trabajo. Según Migliorin, el dispositivo creativo es capaz de crear un "evento" o situación que "desencadena un movimiento no preexistente en el mundo (...) es este nuevo movimiento el que 
producirá un evento no dominado por el artista" (Migliorin, 2005). También, Consuelo Lins, concibe el dispositivo como un "artificio productor de situaciones que serán filmadas" (Lins ,2008, p. 56). En el libro de Lins, O documentário de Eduardo Coutinho: Televisão, cinema e vídeo (2004), el director brasileño Eduardo Coutinho afirma: "filmar diez años, filmar gente de espaldas, en fin, puede ser un mal dispositivo, pero es lo que más importa en un documental" (Lins, 2004, p. 101). Por lo tanto, el dispositivo es entendido aquí como una estrategia autoimpuesta que puede ser más o menos anecdótica pero que "define una metodología, un artificio para que el filme exista" (Ferreira, 2016, p. 72). En este sentido, el empleo del dispositivo creativo sustituye procedimientos habituales de la pre-producción en las prácticas audiovisuales, como el empleo del guion o del découpage y, en parte, también reduce el papel del montaje para ordenar y aportar sentido a las imágenes.

Como en la lógica del juego, en En el parque, se delimita un espacio y un tiempo, se eligen unos "jugadores" y se determinan unas reglas explícitas. El realizador distribuye unas cámaras, y trae la bebida y comida. En definitiva, aporta lo necesario para después participar en su realización como un "actor" más. De esta manera, el control de lo que pueda suceder dentro del dispositivo creado se comparte con los demás participantes, que también graban las imágenes y los sonidos que contendrá la pieza. El trabajo del realizador, como vemos, oscila entre el control absoluto (el establecimiento de las reglas y los límites), y, por otra parte, la "absoluta apertura", la falta de control sobre los derroteros que estos puedan tomar (Migliorin, 2005). Como los escritores del OuLiPo, el sometimiento a unas reglas permite a los realizadores tomar caminos poco transitados e imprevistos, así como abrirse a los acontecimientos fortuitos que puedan surgir dentro del marco creado.

En este sentido, dos de las piezas que hemos tenido como referentes son: $A$ and $B$ in Ontario (1984) de Hollis Frampton y Joyce Wieland, en la que los dos cineastas se abren camino por la ciudad con la única premisa de filmarse el uno al otro; y, Pas à Genève (2014), del colectivo Lacasinegra, en la que este grupo de jóvenes cineastas siguen un protocolo autoimpuesto de filmarse a sí mismos $y$, en base a este intercambio, construyen la película, obviando cualquier tipo de narrativa.

\section{Conclusiones}

En el parque (2021) se relaciona con la tradición del cine experimental y las prácticas video artísticas que conjugan reglas, instrucciones y constricciones para su realización. Esta pieza videográfica subraya la naturaleza depredadora de la mirada voyerista y, articula por medio de un dispositivo creativo (en el que no sólo interviene el aparato técnico, sino también, los actores, el espacio, el tiempo, etc.,) para crear un juego formal que pone en marcha un evento sólo prolongable mientras dure la filmación. La 
creación de un dispositivo no presupone una obra y en principio, tampoco "genera obras buenas ni malas" (Migliorin, 2005). No obstante, el empleo del dispositivo como herramienta narrativa, nos permite omitir parte de los procedimientos o convencionalismos del trabajo audiovisual, así como un exceso de control o guionización de lo que se va a filmar. En su lugar, el uso de un dispositivo de creación nos permite omitir parte de nuestra responsabilidad como realizador de las obras y abrirnos a lo azaroso y lo espontáneo que pueda acontecer durante la grabación.

\section{Referencias}

COMOLLI, J.L. (2001). Sob o risco do real. Catálogo de la 5o Festival de cine documental y Etnográfico de Belo Horizonte.

COMOLLI, J-L. (2008). Ver e poder. A inocência perdida: cinema, televisão, ficção, documentário. Belo Horizonte: Humanitas.

FERREIRA F. (2017). O documentário e o dispositivo nas extremidades do vídeo : estudos em Cao Guimaraes. Extremidades - Experimentos críticos. 1, 68-94.

LINS, C. (2014). O documentário de Eduardo Coutinho. Televisão, cinema e vídeo. Rio de Janeiro: Jorge Zahar.

LINS, C. (2008). Filmar o real. Rio de Janeiro: Zahar.

MIGLIORIN, César (org.). (2010). Ensaios do real. Rio de Janeiro: Azougue Editorial.

MIGLIORIN, C. (2005). O dispositivo como estratégia narrativa. Revista acadêmica de cinema. Digitagrama, n. 3. Disponible en: <http://www.estacio.br/graduacao/cinema/ digitagrama/numero3/cmigliorin.asp>. Aceso em: 15 febrero 2021.

MULVEY, L. (2008). Visual Pleasure and Narrative Cinema. GRIN Publishing.

PHILLIPS S. Sandra (ed). (2010). Exposed: Voyeurism, Surveillance, and the Camera Since 1870. San Francisco/New Haven : Yale University Press.

\section{Películas}

$A$ and $B$ in Ontario. Dir. Joyce Wieland, Hollis Frampton. [16mm]. 1984.

Acidente. Dir. Cao Guimarães, Pablo Lobato. [Video]. Productores: Pablo Lobato, Beto Magalhães. 2006.

Double Blind/No Sex Last Night. Dir. Sophie Calle. [Video]. Productor: Paulo Branco. 1996.

Rape. Dir. John Lennon, Yoko Ono. [16mm]. Productores: John Lennon, Yoko Ono. 1969. 